\title{
Ecosystem-Based Fisheries Management
}

Improving the resilience of ocean ecosystems to support fish populations, coastal communities

The fish on the end of your line, the little forage fish that feed the big fish, the corals that build reef habitats, and the catch of the day in your favorite restaurant are interconnected parts of a vibrant ocean ecosystem. Ensuring the long-term health of important marine species will depend upon our ability to understand and account for the interactions among those species, their environment, and the people who rely upon them for food, commerce, and sport. This comprehensive approach, called ecosystem-based fisheries management, is needed to conserve the healthy ecosystems essential to the sustainability of our fisheries and to deal with the increasingly complex challenges facing our oceans.

The United States is a global leader in fisheries management and has made great strides in ending overfishing (the problem of catching fish faster than they can reproduce) and rebuilding vulnerable populations under the Magnuson-Stevens Fishery Conservation and Management Act-the primary law governing U.S. ocean fisheries. In many regions of our nation, this progress has helped reestablish more abundant fish populations and created economic benefits for the fishing industry and coastal communities.

Core conservation policies added to the law in 1996 and 2007 are fundamental to improving individual fish populations and returning value to fishermen. We must maintain them as the foundation for sustainable management. But the United States should make the transition from a species-by-species approach to ecosystem-based fisheries management to meet the rising and urgent challenges of damaged ocean environments and dynamic, changing oceans.

Our oceans face numerous stresses, including certain fishing practices that damage habitat, global climate change, acidification, and degraded water quality from land-based pollution. Additionally, many fish populations are still struggling to recover from decades of overfishing and poor management.

\section{A solid foundation for management}

In addition to shifting to ecosystem-based fishery management, we must preserve the core conservation provisions of the Magnuson-Stevens Act that have proved so successful:

- End overfishing immediately to keep vulnerable populations from further decline.

- Rebuild depleted populations in as short a time as possible.

- Establish science-based annual catch limits and accountability measures for all federally managed fish species to ensure that overfishing does not occur. 
The resilience of our oceans will depend on our ability to manage the overall health of marine ecosystems. Important habitats must be protected, forage fish must be carefully managed to account for their role in the food web, and the waste of nontarget wildlife, or bycatch, must be reduced.

Ecosystem-based fisheries management integrates these vital components to better conserve the long-term health of our oceans and the communities that depend on them for recreation, employment, and nutrition.

\section{Incorporate ecosystem-based fisheries management into the Magnuson- Stevens Act}

- Reduce waste from bycatch. Bycatch refers to the nontarget fish, marine mammals, birds, turtles, and other wildlife that are caught and then discarded-often dead or dying. Despite legal requirements for managers to report on and minimize bycatch, government scientists estimate that close to 1 out of every 5 pounds of fish taken from the sea is wasted. The law should be strengthened to avoid bycatch, minimize the mortality of these animals, and meet a 1996 provision establishing adequate levels of bycatch monitoring and reporting.

- Protect fish habitats. Coral reefs, fish spawning aggregation sites, and other ocean habitats provide vital areas for fish to reproduce, feed, or take shelter. Very little has been done to reduce damage from destructive fishing practices and nonfishing activities even though the law requires managers to designate and, to the extent practicable, protect essential fish habitats. Congress should enhance habitat protections-including measurable goals and conservation provisions that are reviewed at least every five years-to minimize adverse effects on habitat and to promote restoration and conservation.

- Conserve forage fish. Small fish such as menhaden and sardines are a primary source of food for many species of birds, marine mammals, and large fish-including the striped bass, tuna, and salmon that support important commercial and recreational fisheries. However, forage fish populations are too often managed without adequate consideration of their vital role as prey, or not managed at all. Congress should require managers to protect forage fish with science-based catch limits that account for their unique role in the ecosystem.

- Start smart. Unprecedented shifts in the range and behavior of fish populations due to climate change and the continuing demand for fish will create situations where fishing can expand to new areas, or new species will become fishery targets. Currently, a fishery can begin without adequate information about its potential impacts on the ecosystem or management measures to prevent overfishing and habitat damage. Congress should establish a more common-sense approach that would identify these potential impacts and establish science-based management before fishing is allowed.

- Plan for the whole ecosystem. Fishery management should be guided by ecosystem plans instead of by decisions predominately based on a single species of fish without regard to the health of other species, their common habitat, or impacts on the broader marine environment. While some regional councils have developed ecosystem-based plans, they are typically advisory and inconsistent. The law should be amended to require fishery plans that support more informed management decisions for specific species within the context of the larger ecosystem and encourage policies that maintain healthy and productive fish populations for the long-term benefit of our oceans and coastal communities.

Contact: Ted Morton, director, U.S. oceans, federal Email: wmorton@pewtrusts.org Project website: endoverfishing.org

The Pew Charitable Trusts is driven by the power of knowledge to solve today's most challenging problems. Pew applies a rigorous, analytical approach to improve public policy, inform the public, and stimulate civic life. 